\title{
Homens na docência da educação infantil: uma análise baseada na perspectiva das crianças
}

\author{
Sandro Vinicius Sales dos Santos' (D)
}

\section{RESUMO}

Neste artigo, analisam-se os modos como as crianças atribuem sentidos à presença de um professor homem na educação infantil. O quadro teórico-metodológico articula os novos estudos da infância e os estudos de gênero, servindo como base conceitual de uma etnografia realizada em uma instituição de educação infantil de Belo Horizonte, Minas Gerais, Brasil. Participaram do estudo 25 crianças (sete meninas e 18 meninos), uma professora e um professor. Identificou-se que as relações vividas pelos docentes se baseavam em estereotipias de gênero. A professora, muitas vezes, atribuía parte de suas responsabilidades ao professor, baseando-se, para tanto, em representações da masculinidade hegemônica, fazendo com que as crianças se apropriassem desses significados. Conclui-se que não basta inserir homens na docência com crianças como forma de produzir uma política de equidade de gênero. Para se combaterem preconceitos baseados em diferenças de gênero, é preciso que todos/as se reconheçam como agentes de mudança.

\section{PALAVRAS-CHAVE}

homens; docência; masculinidade; educação infantil; crianças.

'Universidade Federal dos Vales do Jequitinhonha e Mucuri, Diamantina, MG, Brasil. 


\title{
MEN IN CHILDHOOD EDUCATION TEACHING: AN ANALYSIS FROM THE CHILDREN'S PERSPECTIVE
}

\begin{abstract}
In this article, the ways in which children attribute meanings to the presence of a male teacher in early childhood education is analyzed. The theoretical-methodological framework articulates new childhood and gender studies, serving as a conceptual basis for an ethnographic study carried out in an early childhood school in Belo Horizonte, Minas Gerais, Brazil. Twenty-five children ( 7 girls and 18 boys), a female teacher and a male teacher participated in the study. It was identified that the relations established by the teachers were based on gender stereotypes. The female teacher often attributed part of her responsibilities to the male teacher, based on representations of hegemonic masculinity, and causing the children to appropriate these meanings. We conclude that it is not enough to insert men into the teaching of children as a way of producing gender equity policy. In order to combat prejudices based on gender differences, everyone involved must recognize themselves as agents of change.
\end{abstract}

KEYWORDS

men; teaching; masculinity; early childhood education; children.

\section{HOMBRES EN LA DOCENCIA DE LA EDUCACIÓN INFANTIL: UN ANÁLISIS DESDE LA PERSPECTIVA DE LOS NIÑOS}

\section{RESUMEN}

En este artículo se analizan los modos en que los niños atribuyen significados a la presencia de un docente masculino en la Educación Infantil. El marco teórico-metodológico articula los nuevos estudios de la infancia y los estudios de género, sirviendo como base conceptual para una etnografía realizada en una institución de Educación Infantil en Belo Horizonte, Minas Gerais, Brasil. Participaron en el estudio 25 niños (7 niñas y 18 niños), una maestra y un maestro. Se identificó que las relaciones vividas por los docentes se basaban en estereotipos de género. La maestra, muchas veces, atribuía parte de sus responsabilidades al maestro, basándose, por lo tanto, en representaciones de la masculinidad hegemónica, haciendo que los niños se apropien de estos significados. Se concluye que no basta insertar hombres en la docencia con niños como forma de producir una política de equidad de género. Para combatir los prejuicios basados en diferencias de género, es necesario que todos/as se reconozcan como agentes de cambio.

\section{PALABRAS CLAVE}

hombres; docencia; masculinidad; educación infantil; niños. 


\section{INTRODUÇÃO}

Nos tempos atuais, a presença de professores do sexo masculino no exercício da docência em instituições de educação infantil tem ocupado os meios de comunicação, rendendo, até mesmo, intervenções, nem sempre muito assertivas, da classe política. Ao ganhar força e expressividade, a questão vem provocando a investigação e a reflexão crítica por parte da comunidade acadêmica, sendo promotora de muita discussão também no âmbito de creches e pré-escolas.

Apesar de ainda representar um número pouco expressivo, investigações sobre a presença de professores do sexo masculino que atuem com crianças pequenas têm crescido quantitativa e qualitativamente. Esse pequeno progresso está diretamente relacionado ao avanço da produção científica do campo educacional que, entre outras questões, tem objetivado compreender os processos vivenciados por meninos e meninas quando estão entre si e na companhia dos adultos, além de diferentes nuances que envolvem a oferta pública de educação infantil, entre as quais se destacam as complexas dimensões de gênero que atravessam a constituição da profissão docente em creches e pré-escolas.

A produção teórica sobre homens na docência da educação infantil (Cruz, 1998; Sayão, 2005; Ramos, 2011; Monteiro e Altmann, 2014; Silva, 2014; Jaeger e Jacques, 2017; Silva et al., 2018; dentre outros) tem evidenciado as diferenciações demarcadas pelas especificidades do gênero nas relações estabelecidas nesse campo de atuação profissional. Dessa maneira, as pesquisas têm apresentado importantes contribuições para a área, especialmente neste momento da história política, em que as relações de gênero têm figurado no centro do debate nacional, principalmente no campo educacional, impulsionadas por setores ultraconservadores que insistem em retirar direitos historicamente conquistados por grupos minoritários no Brasil ${ }^{1}$.

Se, por um lado, essa produção recente apresenta avanços na investigação sobre a presença/ausência de professores homens na educação e nos cuidados destinados às crianças de até cinco anos, por outro, ainda são escassas as pesquisas que investiguem os modos como meninos e meninas, principais destinatários da política de educação infantil do país, percebem, compreendem e se relacionam com os docentes do sexo masculino com os quais convivem, diariamente, no interior de creches e pré-escolas ${ }^{2}$.

1 A discussão de gênero e sexualidade vem ocupando a agenda política desde a ascensão de movimentos conservadores como o Escola sem Partido que, entre outras questões, têm procurado reverter as políticas de equidade de gênero, conquistas históricas de mulheres e minorias homossexuais no Brasil. A discussão atingiu seu ápice quando, em 2019, as deputadas estaduais Janaína Paschoal, Letícia Aguiar e Valeria Bolsonaro (Partido Social Liberal-São Paulo - PSL-SP) protocolaram o Projeto de Lei No 1174, proibindo profissionais do sexo masculino de realizar cuidados relativos à higiene corporal de bebês e crianças pequenas em instituições de educação infantil (São Paulo, 2019).

2 Ao realizar uma busca no site do grupo de trabalho Educação da Criança de Zero a Seis anos (GT 07) da Associação Nacional de Pós-Graduação e Pesquisa em Educação (ANPEd), foi encontrado um único trabalho (Sousa, 2015) que versa sobre a visão das crianças sobre os professores homens. Tal situação evidencia que o tema constitui lacuna na produção científica nas investigações da área da Educação Infantil. 
Diante disso, este artigo busca contribuir para o campo de estudos sobre docência masculina na educação infantil na medida em que pretende evidenciar o ponto de vista de meninos e de meninas sobre as relações vivenciadas por essas crianças com homens e mulheres no interior da instituição de educação infantil, pois, como constatado, essa abordagem ainda representa uma lacuna na produção acadêmica.

Para tanto, problematizam-se as seguintes questões: como os docentes do sexo masculino, no convívio e na interação com as professoras e com as crianças, protagonizam as relações de gênero? Quais as representações de gênero ${ }^{3}$ que emergem das relações entre homens e mulheres que atuam concomitantemente na docência em creches e pré-escolas? E mais: como as crianças percebem a presença de professores homens na educação infantil? Como as relações de gênero, vivenciadas pelos adultos no contexto de creches e pré-escolas, são apropriadas por meninos e meninas?

Com o objetivo de dialogar sobre essas e outras questões, neste artigo, produzido com dados provenientes de uma tese de Doutorado ${ }^{4}$, busca-se analisar as representações de gênero que surgem nas relações cotidianas em uma instituição de educação infantil e que envolvem, sobretudo, as formas como meninos e meninas percebem as relações vivenciadas pela professora e pelo professor, tarefa realizada por meio de uma aproximação com seus universos de referência.

O texto está dividido em quatro seções. Na primeira, apresenta-se o desenho metodológico no estudo. Em seguida, evidenciam-se os aportes conceituais da pesquisa. Na sequência, são apresentados e discutidos os dados de pesquisa produzidos na interlocução com adultos e crianças durante o trabalho de campo e que permitem evidenciar como as crianças percebiam e atribuíam sentidos à presença de um professor homem entre professoras. Por fim, são apresentadas as considerações finais com o objetivo de contribuir para o debate sobre a presença de professores homens na educação infantil, levando em conta a importância do estabelecimento de relações mais equânimes, baseadas no respeito às diferenças e focadas na multiplicidade de sujeitos que interagem no cotidiano de creches e pré-escolas, especialmente se considerarem-se as questões de gênero como necessárias à compreensão das relações sociais dentro e fora das instituições de educação infantil.

\section{ESCOLHAS METODOLÓGICAS PARA A COMPREENSÃO DA PERSPECTIVA DAS CRIANÇAS SOBRE A DOCÊNCIA MASCULINA}

O desejo de compreender como as crianças percebiam e atribuíam sentido às representações de gênero que emanavam das relações estabelecidas entre a profes-

3 As representações simbólicas de gênero compreendem o conjunto de formas culturalmente organizadas que possibilitam aos sujeitos aludir, classificar, mostrar ou nomear a si mesmos, às pessoas e às coisas com base nas diferenciações historicamente construídas entre a masculinidade e a feminilidade (Santos, 2016, 2017).

4 Trata-se da tese de doutorado intitulada Socialização de gênero na Educação Infantil: uma análise a partir da perspectiva das crianças (Santos, 2016), defendida em outubro de 2016, no Programa de Pós-Graduação Conhecimento e Inclusão Social da Faculdade de Educação da Universidade Federal de Minas Gerais (UFMG), sob a orientação de Isabel de Oliveira e Silva, com apoio financeiro da Coordenação de Aperfeiçoamento de Pessoal de Nível Superior (Capes). 
sora e o professor de uma instituição de educação infantil impôs um duplo desafio de dimensões teórico-metodológicas. Do ponto de vista teórico, fez-se necessário construir aportes capazes de ampliar a acuidade visual diante das especificidades etárias das crianças. Assim, para analisar os sentidos produzidos por meninos e meninas de cinco anos de idade sobre as relações de gênero vivenciadas no interior de uma instituição pública de educação infantil, foi necessário articular, para além de teorias e de autores/as dos novos estudos da infância (Thorne, 1993; Morrow, 2006; Alderson, 2008; entre outros/as), autores/as dos estudos feministas e de gênero (West e Zimmerman, 1987; Connell e Messerschmidt, 2013; Connell e Pearse, 2015; Connell, 2016; entre outros/as).

Em consonância com tal arcabouço teórico, foi igualmente imprescindível definir um desenho metodológico que permitisse aproximações com os sentidos sociais produzidos pelas crianças sobre as relações de gênero. Desse modo, no plano metodológico, foi preciso empreender uma leitura interpretativa da experiência das crianças por meio da alteridade da infância. Para tanto, elaborou-se um desenho para a investigação que permitiu compreender as especificidades das experiências sociais de gênero vivenciadas por adultos e crianças na instituição.

Por meio da realização de uma etnografia (Spradley, 1979; Geertz, 1989; Graue e Walsh, 2003) em tal instituição, preocupou-se em acessar a perspectiva das crianças com o objetivo de apreender os modos complexos e multifacetados que elas possuem de compreender e, em certo sentido, de vivenciar as relações de gênero, seja na relação com os pares, seja na interação com os adultos. As descrições etnográficas desenvolvidas na interlocução com essas crianças permitiram compreender os significados que elas "constroem nas suas ações situadas de todos os dias, isto é, situadas no contexto cultural e nos estados mutuamente intencionais de interação dos participantes" (Graue e Walsh, 2003, p. 59).

O trabalho de campo foi realizado de março a dezembro de 2015 em uma escola municipal de educação infantil (EMEI) localizada em um bairro da periferia da cidade de Belo Horizonte, Minas Gerais. O processo de produção de dados no âmbito da empiria contou com a participação de 25 crianças (18 meninos e sete meninas) de cinco anos de idade, a professora de referência e o professor de apoio da turma ${ }^{5}$. Como forma de ter acesso ao ponto de vista das crianças, fez-se necessário articular a observação participante e os registros em caderno de campo a outras técnicas de produção de dados (Cohn, 2005). Nesse sentido, também foram produzidos pelas crianças desenhos que, ao serem conjugados com suas falas, permitiram interpretar as diferentes formas como as relações de gênero vivenciadas por sua professora e seu professor eram percebidas por meninos e meninas. Além disso,

$5 \mathrm{Na}$ organização da educação infantil belo-horizontina, os/as professores/as referência são aqueles/as que passam a maior parte do tempo com a turma e, geralmente, respondem administrativa e pedagogicamente por ela. Já os/as professores/as de apoio são aqueles/as que habitualmente "passam" pela turma diariamente - nos momentos em que os professores/as referência saem de sala para as atividades coletivas de planejamento e avaliação do trabalho escolar (ACPATE). Esse tempo corresponde a um terço da jornada de trabalho e cumpre a determinação da Lei de Diretrizes e Bases (LDB) - Lei no 9.394, de 20 de dezembro de 1996, e da Lei no 11. 738, de 16 de julho de 2008 (respectivamente Brasil, 1996, 2008). 
foram realizadas entrevistas com as crianças como forma de compreender as especificidades das relações de gênero vividas por adultos e crianças naquele contexto. A articulação entre os dados provenientes de tais instrumentos de pesquisa foi realizada com o objetivo de viabilizar a construção de uma descrição densa (Geertz, 1989) acerca dos processos sociais que, mediados pelas relações de gênero, eram vivenciados pelas crianças e por seus professores na instituição.

A conjugação entre esses diferentes instrumentos de pesquisa permitiu uma leitura interpretativa das experiências das crianças no que concerne às relações de gênero na docência de homens e de mulheres no contexto da instituição de cuidados e educação - o que ratifica a relevância da triangulação de dados na pesquisa com crianças (Graue e Walsh, 2003; Rocha, 2008). A análise das relações de gênero por diferentes ângulos (instrumentos) e pela perspectiva de diferentes atores (adultos e crianças) permite melhor compreensão das especificidades das aprendizagens relativas à construção da masculinidade e da feminilidade, uma vez que "um bom registro de dados contém pontos de vista recolhidos de tantas perspectivas quanto possível" (Graue e Walsh, 2003, p. 127).

\section{SITUANDO A QUESTÃO DOS PROFESSORES HOMENS NO DEBATE CONTEMPORÂNEO SOBRE GÊNERO E MASCULINIDADES}

Estudos que evidenciam a presença masculina na docência da educação infantil, embora não sejam consensuais, apresentam alguns pontos positivos: seja pelo fato de ampliarem as noções de masculinidades das crianças, já que se trata de homens que cuidam (Cruz, 1998), seja por apresentarem uma visão otimista em relação à valorização profissional (Sayão, 2005) ou por demonstrarem alterações, ainda que tímidas, nas relações cotidianas entre homens e mulheres (Jaeger e Jacques, 2017). No entanto, nessas mesmas investigações, há o receio de que esses profissionais apresentem perigo às crianças e, por isso, tenham sua reputação colocada em suspeita pela comunidade escolar (Ramos, 2017).

Há, contudo, outras especificidades que envolvem esse grupo de pesquisas emergentes na produção acadêmica do campo educacional. Entre os principais temas investigados estão: as trajetórias de vida dos professores homens que atuam na educação infantil (Monteiro e Altmann, 2014; Jaeger e Jacques, 2017); as formas de inserção dos professores do sexo masculino em uma profissão majoritariamente feminina (Sayão, 2005; Silva, 2014); e as estratégias utilizadas por esses professores para permanecerem na docência com crianças pequenas (Ramos, 2011, 2017).

Em relação à escolha da profissão, Monteiro e Altmann (2014) afirmam que há uma heterogeneidade de percursos trilhados pelos professores homens que decidem assumir a docência em creches e pré-escolas como lócus de atuação profissional. Para as autoras, as razões de escolha da profissão pelos docentes do sexo masculino incluem desde a decisão precoce — inspirada na atuação de parentes próximos nas carreiras do magistério (mães, tias, familiares e amigos/as) — até a chegada tardia ao trabalho docente — após um amplo percurso marcado por diferentes ocupações profissionais. Apesar disso, é preciso considerar que há pontos em comum na in- 
serção dos professores homens no espaço profissional da educação e dos cuidados destinados às crianças de até cinco anos e onze meses.

Para Ramos (2011), apesar de os professores homens, muitas vezes, trilharem trajetórias distintas de inserção na carreira docente, todos eles passam por um processo complexo de aceitação. $\mathrm{O}$ autor analisou como os professores homens da rede pública de Belo Horizonte se inserem e buscam, diariamente, manter-se na docência da educação infantil. Ramos (2011) considera que, para além do estágio probatório - intrínseco ao serviço público -, esses profissionais passam também por outro processo avaliativo, denominado por ele de período comprobatório - tempo de atuação no qual os professores homens precisam "provar" que, além de possuírem habilidades para cuidar das crianças e educá-las, são sujeitos idôneos, de sexualidade ilibada e que, portanto, não oferecem riscos à integridade física e sexual de meninos e meninas (Ramos, 2011, 2017). O autor defende ainda que esse período de comprovação se conforma como um conjunto de rituais que possibilita a aceitação dos professores homens como parte constitutiva do corpo docente daquelas instituições.

Contudo, ainda que os professores homens sejam aceitos pelos diferentes atores que se encontram cotidianamente na instituição de educação infantil (professoras, gestoras, crianças e familiares), eles são vistos como pares-díspares, pois, embora comprovem possuir habilidades pedagógicas como as professoras, sempre serão observados em função de uma suposta ameaça à sexualidade de meninos e de meninas, seja pela possibilidade de abusarem sexualmente das crianças, seja por serem considerados uma referência perniciosa do ponto de vista da produção da sexualidade dos pequenos, especialmente dos meninos. Dessa forma, poucos são os professores homens que, no contato com mulheres e crianças na educação infantil, conseguem impedir que as diferenças se tornem desigualdade, contribuindo, assim, para a construção de relações mais equânimes e igualitárias entre homens e mulheres e entre adultos e crianças.

Por isso, é preciso considerar que, em decorrência das especificidades históricas constitutivas da docência na educação infantil, o cotidiano de creches e pré-escolas é marcado por representações femininas, expressas na visão de mundo de suas profissionais. Como dito, diferentemente do magistério exercido nos demais níveis de ensino, a docência em creches e pré-escolas nasceu como ocupação profissional efetivamente feminina, por tratar-se de uma demanda social de mulheres trabalhadoras que foi, em um primeiro momento, acolhida por grupos de mulheres também oriundas das classes populares (Vieira, 1986; Cerisara, 2002). Desse modo, o ambiente da instituição de cuidado e educação "é concebido e organizado por mulheres cujas concepções informam o conjunto das relações que ali se estabelecem. As representações de feminino e de masculino com as quais as crianças se relacionam são, em grande medida, as representações de suas educadoras" (Silva e Luz, 2010, p. 24).

Assim, quando um profissional do sexo masculino adentra esse espaço de atuação profissional, ele passa a alterar as relações de gênero que ali circulam (Ramos, 2011), podendo tanto atuar no processo de produção de novos sentidos sobre as masculinidades e as feminilidades quanto reforçar estereótipos sociais. Tal posicionamento dependerá do quanto os sujeitos (homens e mulheres) inseridos na instituição de educação infantil se reconheçam como agentes transformadores das diferenças de gênero. 
Neste estudo, meninos e meninas são concebidos como sujeitos sociais competentes e com potencial para intervir nas relações em que se encontram, mostrando-se igualmente capazes de falar em seu próprio direito (Alderson, 2008; Carlos, 2008). Nesse sentido, é preciso considerar que a presença de um professor do sexo masculino em meio a um conjunto de professoras não passa despercebida pelas crianças, que passam a significar as relações de gênero não somente pelas vias das representações femininas, mas também pela presença do professor homem e das relações que ele estabelece com as professoras.

Nesse contexto, o conceito de gênero e suas derivações configuram-se como construtos teóricos capazes de evidenciar as nuances em torno das relações entre as professoras e seus pares/díspares, os professores homens. Mais ainda, permite lançar luzes sobre os modos pelos quais as crianças percebem e significam as representações de gênero que emanam de tais relacionamentos sociais.

Como categoria de análise, o gênero é compreendido como uma performance cotidiana aberta à reflexão e ao questionamento (West e Zimmerman, 1987). Trata-se, pois, de uma construção que, apesar de subjetiva, é simultaneamente sistemática, recorrente e estabelecida de modo interpessoal (Connell e Pearse, 2015). A compreensão do gênero decorre da apropriação de um conjunto de práticas sociais nas quais os indivíduos se constroem na qualidade de homens e mulheres, meninos e meninas, ao passo que, nas situações cotidianas, constroem também as relações de gênero. Compreende-se o gênero, portanto, como consequência da tessitura de uma rede de significados culturais, histórica e socialmente elaborada sobre e com base nos modos como os corpos são socialmente significados, ao mesmo tempo que são respectivamente construídos (West e Zimmerman, 1987; Connell e Pearse, 2015; Connell, 2016).

No contexto da educação infantil - espaço social estruturado pelo adulto para as crianças -, as representações de gênero colocam-se como dimensão estruturante das relações sociais. Logo, o gênero é compreendido como uma estrutura social que possui dimensões específicas, pois enfoca uma multiplicidade de práticas culturais que regulam, adéquam e ajustam as diferenciações entre os corpos - de homens e de mulheres, de meninos e de meninas (Connell e Pearse, 2015), embora seja necessário reconhecer que existe uma diversidade de outros modos de ser e estar no mundo que ultrapassam esse dualismo ${ }^{6}$.

Connell e Pearse (2015) buscam compreender os modos pelos quais a agência (que transcorre por meio de práticas corporais) e as estruturas sociais se interconectam. Segundo as autoras, as relações de gênero "somam-se ao processo histórico no qual a sociedade é corporificada e os corpos são arrastados para a história" (Connell e Pearse, 2015, p. 112), percurso que elas nomeiam como corporificação social. Assim, à medida que se vivenciam as práticas sociais (que se passam no e pelos corpos), por meio da regularidade das ações, contribui-se para o enrijecimento da estrutura de gênero. $\mathrm{O}$ conceito de corporificação social permite compreender tanto a assimétrica

6 É preciso levar em conta que, na atualidade, presencia-se a emergência de diferentes sujeitos na cena social e, nesse sentido, há pessoas que não se encaixam nessa polaridade, como os andrógenos, os transex, intersex, enfim, homens e mulheres em processo de desconstrução do binarismo de gênero. 
inserção dos corpos de homens e mulheres nas dinâmicas sociais quanto a introjeção dos processos sociais nos corpos desses indivíduos (Connell, 2016).

Para compreender a corporificação social, Connell (2016) explica que é preciso considerar que a agência humana (capacidade de ação social) é um ato corpóreo que, por meio de sua regularidade, permite a reprodução das estruturas condicionantes das relações sociais. Assim, reconhecer a regularidade dessas interações permite compreender as dinâmicas societais que resultam das diferenças sexuais, produzindo um enfoque capaz de identificar a criação de realidades socioculturais ao longo do tempo, já que "as estruturas sociais estão sempre em processo de construção, contradição e transformação" (Connell, 2016, p. 49). Desse modo, compreende-se que:

A corporificação social não é mero reflexo, nem apenas uma reprodução, nem somente uma citação. É um processo que gera, a cada momento, novas realidades históricas: novas possibilidades corporificadas, experiências, limitações e vulnerabilidades para as pessoas envolvidas. (Connell, 2016, p. 49)

Apesar de algumas tradições teóricas considerarem o termo "gênero" como sinônimo ou até substitutivo de "mulheres", não podemos esquecer que homens participam desde meninos das relações de gênero e, por conseguinte, padrões de masculinidade são produzidos por meio da corporificação social. Nessa perspectiva, Connell (2016) afirma que as masculinidades são padrões socialmente construídos por meio das práticas sociais provenientes das relações de gênero. A autora fala de masculinidades (no plural), pois considera que classe, raça e etnia, diferenças regionais e geracionais atravessam as categorias "homens" e "masculinidades", distribuindo os lucros e os dividendos das relações de gênero de modo desigual entre os homens. $\mathrm{Na}$ visão dessa autora, é isso que explica não só a existência da masculinidade hegemônica (aquela que prevê e promove a dominação dos homens sobre as mulheres), mas também de masculinidades cúmplices (não alinhadas com os pressupostos hegemônicos da dominação masculina, mas que, ainda assim, deles tiram proveito) e de masculinidades subordinadas (diretamente contrapostas às visões hegemônicas do conceito). Embora essa classificação possa dar, em princípio, a falsa impressão de relativização ao conceito, é preciso considerar que:

A masculinidade não é uma entidade fixa encarnada no corpo ou nos traços da personalidade dos indivíduos. As masculinidades são configurações de práticas que são realizadas na ação social e, dessa forma, podem se diferenciar de acordo com as relações de gênero em um cenário social particular. (Connel e Messerschmidt, 2013, p. 244)

Embora, desde meninos, os homens tenham acesso, via processos de socialização ${ }^{7}$, a padrões hegemônicos ou dominantes de masculinidade, eles convivem

7 A socialização de gênero consiste na conjugação de diferentes processos socializadores com vistas a produzir sujeitos gendrados. Na conjugação desses processos, as crianças, na qualidade de sujeitos ativos, interagem com os adultos, com seus pares, com a cultura e com a sociedade pautadas por um quadro de referências ambíguo, conflituoso e, por vezes, contraditório (Santos, 2016, 2017, 2018). 
também com outras possibilidades de vivenciar a masculinidade, envolvendo, muitas dessas experiências, relações mais igualitárias e respeitosas com meninas e mulheres - como é o caso dos professores homens que optam por atuar na educação infantil.

Assim, ao reconhecer-se a capacidade de ação social das crianças e de participação ativa nas dinâmicas societais, é possível compreender que meninos e meninas podem usar estrategicamente definições convencionais de masculinidades e de feminilidades dominantes (Thorne, 1993; Morrow, 2006; Connell, 2016) que são emanadas pelas relações de gênero vividas pelas professoras e pelo professor do sexo masculino, em vez de serem rigidamente regulados por elas. Desse modo, meninos e meninas são considerados/as sujeitos ativos que, tanto no plano individual quanto na esfera da vida coletiva, tornam-se capazes de falar, por seus próprios méritos, sobre as experiências sociais que partilham com seus pares e com os adultos (Alderson, 2008; Carlos 2008; Connell, 2016). Não se comportam, nesse sentido, como seres passivos aos processos de socialização que vivenciam, já que suas ações conformam práticas sociais. Meninos e meninas extraem sentidos e significados de um amplo arcabouço cultural (que envolve, entre outros fatores, linguagem, elementos materiais e simbólicos, instituições e estruturas sociais diversificadas), podendo ser (ou não) fortemente restringidos por elas. Essa perspectiva torna-se útil quando se verifica que a presença de professores homens é um fator que altera a configuração da estrutura de gênero da instituição de educação infantil (Santos, 2016).

É preciso reconhecer, pois, que as masculinidades são produzidas ao longo do tempo com base nas apropriações que crianças e jovens realizam das relações de gênero. E, como as estruturas de gênero se diferenciam entre sociedades e grupos sociais mudando ao longo do tempo (Connell, 2016), haverá uma diversidade de representações de masculinidades quando as crianças, no contexto da instituição de educação infantil, se depararem com a presença de um homem entre as professoras.

\section{LIMITES E POSSIBILIDADES DA PRESENÇA MASCULINA COMO INSTRUMENTO DE PRODUÇÃO DE EQUIDADE DE GÊNERO NA EDUCAÇÃO INFANTIL}

Sendo o gênero uma categoria relacional, parte-se do pressuposto de que a presença de homens na docência com crianças pequenas não é somente significada por esses sujeitos. No cotidiano, mulheres e crianças, ao interagirem com esses profissionais, produzem sentidos e contribuem para a tessitura de uma rede semiótica (Geertz, 1989) sobre a presença masculina na educação infantil, que se constitui com base nos universos de referência desse coletivo.

Connell (2016) considera que a construção das masculinidades envolve a posição social dos homens combinada às suas histórias de vida. Tais dimensões, quando associadas ao conjunto de experiências sociais por eles vivenciadas, constituem o principal lócus de produção das masculinidades. Assim, as relações vividas pelo professor e pela professora no contexto da educação infantil são apropriadas pelas crianças, que passam a partilhar dos significados sociais que ali circulam. Desse modo, as representações de masculino e de feminino que emergem das relações 
vivenciadas pelo professor e pela professora não passam incólumes pelas crianças e, nesse sentido, também foram apreendidas pelos/as pequenos/as. No âmbito da conversa sobre a produção dos desenhos, algumas crianças deixam claro que o professor Anselmo ${ }^{8}$ possuía mais "controle" e vigilância sobre eles/as do que a professora Vânia, conforme se pode observar em algumas falas das crianças, produzidas de modo articulado aos seus desenhos (Figuras 1 e 2):

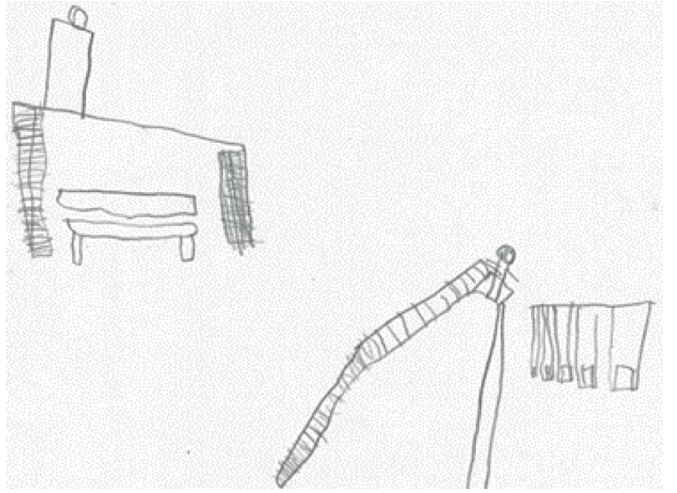

Figura 1 - Desenho de Vitório.
Pesquisador: - E qual o professor ou a professora de que você mais gosta da UMEI? Vitório: - O Anselmo.

Pesquisador: - E por que você gosta mais dele? Vitório: - Ah... é assim... ele é mais bravo que a Vânia. Ele xinga mais. Ele xinga até quando a Vânia chama ele para brigar com a gente. Só que tem que ele traz umas brincadeiras legais pra gente. (Vitório - desenho: "Eu na UMEI”, 25 de agosto de 2015).

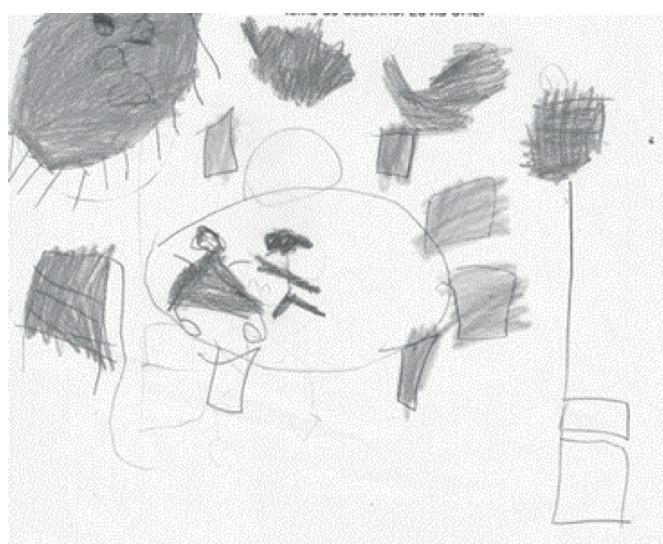

Figura 2 - Desenho de Karolina.
Pesquisador: - E adulto? Qual é o adulto de que você mais gosta na UMEI?

Karolina: - Hum... a Vânia. Só da Vânia que eu gosto.

Pesquisador: - Só dela? E de mais ninguém? Karolina: - Ab, tem o Anselmo... eu até gosto dele, mas só que tem é que ele fica bravo com as crianças, tem vezes. (Karolina - desenho: "Eu na UMEI", 25 de agosto de 2015).

Essa percepção sobre o maior controle e uma postura mais rigorosa do professor Anselmo do que da professora Vânia também foi pauta de reflexão nas entrevistas com as crianças: "O Anselmo é bem mais bravo que a Vânia. Ele sempre fala bravo com a gente. Se a gente faz bagunça, a Vânia chama ele” (Gláucia, 7 de maio

8 Por questões de ordem ética, os nomes dos/as participantes (adultos e crianças) foram substituídos por nomes fictícios, como forma de preservar o anonimato e a confidencialidade das informações prestadas aos/às interlocutores/as. 
de 2015); "O Anselmo me dá castigo de vez em quando. Quando eu falo que não fizo para casa, o Anselmo me póe de castigo. Tem vezes que até a Vânia pede para ele me pôr de castigo" (Saulo, 21 de setembro de 2015).

Esses excertos de pesquisa apresentam evidências de que, em muitos casos, o que distingue e diferencia mulheres e homens nas interações cotidianas justifica-se em função de representações que, apesar de simbólicas, não são necessariamente compreendidas no campo das construções sociais, das quais homens e mulheres, meninos e meninas são parte ativa - fator que contribui para a naturalização dessas diferenças. Desse modo, tanto nos diálogos que sucedem à produção dos desenhos de Vitório e Karolina quanto nas entrevistas de Gláucia e Saulo, duas questões desvelam-se sobre as relações vividas pelos professores: uma maior rigidez do professor Anselmo em relação à sua companheira de profissão, e a concessão que a professora Vânia realiza ao fazer dessa suposta autoridade de seu colega sobre os pequenos um mecanismo de controle dos comportamentos das crianças.

Esses dados evidenciam que, no caso deste estudo, a presença de um professor homem, finamente adaptado às exigências do coletivo institucional, portanto aceito pela comunidade escolar (Ramos, 2011) e que, em decorrência disso, também se responsabiliza pelos cuidados e pela educação das crianças na instituição em análise, traz novas implicações para pensar as representações de gênero que circulam nesse contexto. As relações vivenciadas entre o professor e a professora produzem representações sobre as masculinidades e as feminilidades que, se não forem tomadas como alvo de questionamento e reflexão coletiva, podem contribuir para a reprodução de estereótipos oriundos de outros contextos sociais no interior de creches e pré-escolas. O episódio a seguir demonstra como a docente, em determinadas situações do cotidiano, transferia ao professor homem responsabilidades que eram suas, como professora de referência da turma. Percebe-se que, muitas vezes, ela associava rigor, domínio e autoridade ao professor Anselmo - imagens comumente associadas a representações da masculinidade hegemônica (Connell, 1995; Connell e Messerschmidt, 2013) - como forma de barganhar o bom comportamento das crianças, buscando manter, desse modo, controle sobre as ações de meninos e meninas:

Como hoje pela manhã ventava muito, a Professora Vânia decidiu não levar as crianças ao parquinho. Ela resolveu passar um filme na sala de vídeo. Após o término do DVD, meninos e meninas perguntam à professora se todos iriam ao parquinho. A professora Vânia lhes respondeu que, primeiro, eles fariam um cartão em comemoração ao dia das mães. A professora falou que poderia tentar "convencer" o professor Anselmo a levar a turma para o parquinho se todo mundo se comportasse direitinho. As crianças se acalmaram por um momento, mas logo voltaram a realizar brincadeiras e outras interações entre si. Como estavam muito agitadas ao término da confecção do cartão e se aproximava das 10h (horário de o professor Anselmo assumir a turma), a professora Vânia, a fim de que as crianças ficassem quietas e mais calmas, falou em tom alto para toda a turma:

Professora Vânia: "Gente, gente... O Anselmo já está vindo aí. Ai... ai... ele não vai gostar nadinha desse comportamento. E é assim que vocês querem que eu conven- 
ça a ele, né?". As crianças então começaram a se assentar e abaixarem suas cabeças aguardando a chegada de Anselmo, que, atendendo à solicitação de Vânia, não levou a turma ao parquinho em função do mau comportamento. (Notas do Caderno de campo, 7 de maio de 2015).

Como se pode perceber nesse episódio, por duas vezes a professora falou para as crianças que quem decidiria se elas iriam (ou não) para o parquinho seria o professor Anselmo. Em um primeiro momento, quando as crianças pediram para brincar no espaço externo, a professora afirmou que poderia "tentar 'convencer' 0 professor Anselmo a levar a turma para o parquinho se todo mundo se comportasse direitinho". Mais adiante, após o término da confecção do cartão em comemoração ao Dia das Mães, frente à inquietude das crianças, a professora reafirmou o "hipotético poder" de Anselmo para decidir se as levaria ao parquinho ao dizer: "Gente, gente... O Anselmo já está vindo aí. Ai... ai... ele não vai gostar nadinha desse comportamento. E é assim que vocês querem que eu convença a ele, né?".

Nas duas situações, Vânia utiliza o "suposto poder" de Anselmo para agenciar o bom comportamento das crianças. Essa situação evidencia que, desde muito cedo, as crianças convivem nas instituições educacionais com representações que promovem a ideia de que a diferenciação entre o masculino e o feminino é marcada por noções essencialistas e distintas, as quais afirmam que "as mulheres são, por natureza, mais delicadas, dóceis aptas ao cuidado de crianças do que os homens. Esses por sua vez, são representados pela virilidade força e coragem, atributos desnecessários à educação e ao zelo por crianças" (Jaeger e Jacques, 2017, p. 546-547).

No âmbito das entrevistas, o professor e a professora, em certo sentido, confirmaram aquilo que foi registrado na observação participante. Quando perguntados sobre como viam a relação das crianças com seu companheiro/a de trabalho, Anselmo e Vânia deram respostas cuja compreensão permite interpretar que as relações que ele e ela estabelecem entre si sugerem formas, por vezes estereotipadas, de representar as masculinidades e as feminilidades. Segundo os professores:

Fica parecendo uma relação familiar, de pai e mãe. Eu sou aquela pessoa que... eu vou sempre ceder. Muitas vezes, eu vou fazer ou falar alguma coisa e as crianças: "Não, professora, porque o Anselmo...". Ai eu digo assim: "Quando o Anselmo chegar, eu vou perguntar a ele se vocês merecem!". Ai, por exemplo, o Mário fala assim: “Ah!!! Então a gente não vai, não!". (Professora Vânia, 6 de outubro de 2015).

Acho que isso é algo que já vem (mais ou menos) de casa. Acho que está na nossa cultura mesmo de que é o pai que põe a ordem, impóe respeito. Já a mãe é sempre mais amorosa, mais acolhedora. E, na sala, isso é claro mesmo. Fica mesmo muito claro quando a Vânia traz essas situações do dia a dia. (Professor Anselmo, 6 de outubro de 2015).

Nesses trechos das entrevistas, a professora Vânia afirma que Anselmo possui mais controle ou "domínio" sobre o comportamento das crianças do que ela. A professora, inclusive, confirma que usa a "suposta" posição de autoridade do professor sobre as crianças ao relatar sua fala para Mário, uma das crianças da turma: "Quandoo 
Anselmo chegar, eu vou perguntar a ele se vocês merecem?". Anselmo, por seu turno, justifica suas ações e afirmações alegando que essa postura, assumida tanto por ele quanto por ela, é de ordem das produções culturais, pois afirma que a questão "está na nossa cultura mesmo; de que é o pai que põe a ordem, impóe respeito. Já a mãe é sempre mais amorosa, mais acolhedora". É preciso considerar que as reflexões realizadas pelo professor e pela professora no âmbito das entrevistas coletivas apontam para o fato de que tais ações são

produto de uma cultura, das relações sociais nas quais [ela] se socializou e nas quais aprendeu/construiu referências sobre feminino e masculino, sobre o permitido e o não permitido a meninos e a meninas. Ela parece oscilar entre a profissional e a mãe, como duas identidades que entram em conflito no que concerne às práticas educativas com meninos e meninas. (Silva e Luz, 2010, p. 35)

Assim, as relações pedagógicas entre crianças e adultos na educação infantil (que articulam práticas sociais de cuidados e educação) são produzidas pelas docentes que as organizam, com base em concepções provenientes de "experiências sociais mais amplas, nas quais as educadoras [e os educadores] constroem suas concepções de masculino e de feminino" (Silva e Luz, 2010, p. 27). Assim como as professoras participantes da pesquisa de Silva e Luz (2010), percebe-se que o professor Anselmo assume uma postura diante das crianças que alterna entre as imagens do profissional e a do pai.

O conjunto dos dados produzidos no âmbito do trabalho de campo evidencia duas importantes questões que envolvem a inserção de homens na docência da educação infantil. Os excertos de pesquisa apresentados evidenciam que o professor do sexo masculino, em muitas situações, demarca a sua diferença em relação às professoras por meio da produção de uma pedagogia dura, isto é, um conjunto de práticas de educação e de cuidado que se diferencia daquele realizado pelas mulheres, já que se pauta por elementos da masculinidade hegemônica, sendo, portanto, marcado pela rigidez, pela imposição da autoridade e, sobretudo, pelo disciplinamento e pelo controle dos corpos das crianças. Assim, ainda que aceitos pelos diferentes atores sociais presentes no contexto da educação infantil (professoras, crianças, pais, mães e familiares, gestores/as, entre outros/as), os professores homens apresentam-se como pares-díspares na medida em que tanto eles quanto as professoras tendem a reforçar essa diferença.

A segunda questão, que decorre da primeira, diz respeito à falta de um debate institucional sobre as questões de gênero no contexto investigado, especialmente quando se tem um professor do sexo masculino atuando nos cuidados e na educação das crianças de até cinco anos de idade. Considera-se não só a necessidade de as questões de gênero figurarem no projeto pedagógico das instituições, mas que elas sejam alvo de debate e reflexão crítica por parte de docentes (homens e mulheres), conformando-se como força motriz para a construção de uma sociedade mais igualitária e justa, expressando um projeto de formação humana que não permita a transformação da diferença em desigualdade.

Em suma, por meio da aproximação com os universos de referência de meninos e de meninas, bem como das percepções que eles e elas possuem sobre as 
relações de gênero vivenciadas por seus professores na educação infantil, a compreensão é a de que não basta apenas inserir homens na docência, é necessário que os/as profissionais da educação de modo geral (homens e mulheres) se reconheçam como agentes de mudança no que tange às relações de gênero.

\section{AFINAL, É PRECISO TER HOMENS NA DOCÊNCIA DA EDUCAÇÃO INFANTIL?}

Este artigo problematizou os modos como cotidianamente meninos e meninas, homens e mulheres produzem sentidos sobre a docência masculina no contexto da educação infantil. Nele, ficou evidente que os professores homens, quando inseridos em um ambiente profissional construído por e em função de uma demanda social das mulheres, alteram as relações sociais que ali ocorrem.

Compreende-se que "a docência na Educação Infantil é construída por meio do trabalho diário de homens e mulheres, e não está determinada por uma estrutura de gênero" (Jaeger e Jacques, 2017, p. 550), ainda que ela seja determinante para a gênese da função docente em creches e pré-escolas, uma vez que se trata de uma atividade profissional originalmente concebida, produzida e exercida por mulheres. Desse modo, como construções cotidianas, as relações entre homens e mulheres podem evocar distintas expressões de masculinidades e feminilidades como fruto de processos que, além de relacionais, assumem potencial pedagógico na medida em que encerram possibilidades variadas de ser e de estar no mundo, com vistas às relações de gênero e que podem ser apresentadas às crianças desde a mais tenra idade. Entretanto, há de se ter conhecimento sobre o lugar social que homens e mulheres que se propõem a cuidar e a educar as crianças ocupam e quais as possibilidades de realizar essa tarefa de modo pleno sem, contudo, reproduzir estereotipias sociais em torno das masculinidades e das feminilidades.

Importante destacar que as relações de gênero, por serem fluidas e dinâmicas, na educação infantil são vividas pelos diferentes sujeitos (adultos e crianças; meninos e meninas; homens e mulheres) de formas ambíguas e, por vezes contraditórias. Seria, portanto, relevante que as questões de gênero, bem como o debate sobre a presença de professores homens, estivessem efetivamente inseridos no plano de trabalho das/os docentes (assim como nos projetos pedagógicos das instituições de educação infantil), contrariando posicionamentos de setores da sociedade que, na atualidade, mobilizam-se e reivindicam a supressão da expressão "ideologia de gênero" dos currículos das instituições de cuidado e de educação.

Em suma, não é suficiente apenas inserir profissionais do sexo masculino na docência de crianças pequenas como forma de produzir uma política de equidade de gênero. Para combaterem-se preconceitos baseados nas representações de gênero, não basta somente assegurar a presença de professores homens na educação e nos cuidados desenvolvidos no âmbito da educação infantil; não basta ser homem ou mulher, pois, para além da condição humana, é necessário que o respeito às diferenças - de qualquer natureza - seja uma discussão permanente em qualquer uma das etapas de formação das pessoas (não apenas no âmbito da educação escolar), mas que seja, sobretudo, um debate constante na educação infantil. 
Nesse processo, faz-se necessário que todos e todas, indistintamente, tanto homens quanto mulheres, estejam imbuídos/as do desejo de mudança e reconheçam-se como sujeitos implicados em processos de transformação social, especialmente aqueles referentes à construção, à desconstrução e à reconstrução das relações sociais de gênero.

\section{REFERÊNCIAS}

ALDERSON, P. Children as researchers: the effects of participation rights on research methodology. In: CHRISTENSEN, P.; JAMES, A. (org.). Research with children: perspectives and practices. 2. ed. Londres: Routledge, 2008. p. 271-290.

BRASIL. Lei no 9.394, de 20 de dezembro de 1996. Estabelece as diretrizes e bases da educação nacional. Diário Oficial da União, Brasília, seção 1, n. 248, p. 27833-27841, 23 dez. 1996.

BRASIL. Lei no 11.738, de 16 de julho de 2008. Regulamenta a alínea "e" do inciso III do caput do art. 60 do Ato das Disposições Constitucionais Transitórias, para instituir o piso salarial profissional nacional para os profissionais do magistério público da educação básica. Brasília: Presidência da República, Casa Civil, Subchefia para Assuntos Jurídicos, [2008]. Disponível em: http://www.planalto.gov.br/ccivil_03/_ato2007-2010/2009/lei/ 111947.htm. Acesso em: 12 fev. 2021.

CAMPOS, M. M. Por que é importante ouvir a criança? A participação das crianças pequenas na pesquisa científica. In: CRUZ, S. H. V. (org.). A criança fala: a escuta de crianças em pesquisas. São Paulo: Cortez, 2008. p. 35-42.

CERISARA, A. B. Professoras de educação infantil: entre o feminino e o profissional. São Paulo: Cortez, 2002. (Coleção Questões da Nossa Época).

COHN, C. Antropologia da criança. São Paulo: Jorge Zahar, 2005.

CONNELL, R. W. Políticas da masculinidade. Educação \& Realidade, Porto Alegre, v. 20, n. 2, p. 185-206, jul./dez. 1995.

CONNELL, R. Gênero em termos reais. Tradução: Marília Moschkovich. São Paulo: nVersos, 2016.

CONNELL, R. W.; MESSERSCHMIDT, J. W. Masculinidade hegemônica: repensando o conceito. Estudos Feministas, Florianópolis, v. 21, n. 1, p. 241-282, jan./ abr. 2013. http://dx.doi.org/10.1590/S0104-026X2013000100014

CONNELL, R.W.; PEARSE, R. Gênero: uma perspectiva global. Tradução e revisão técnica: Marília Moschkovich. São Paulo: nVersos, 2015.

CRUZ, E. F. "Quem leva o nenê e a bolsa?": o masculino na creche. In: ARILHA, M.; RIDENTI, S. G. U.; MEDRADO, B. (org.). Homens e masculinidades: outras palavras. São Paulo: Ecos/34, 1998. p. 235-255.

GEERTZ, C. A interpretação das culturas. Rio de Janeiro: LTC, 1989.

GRAUE, E.; WALSH, D. J. Investigação etnográfica com crianças: teoria, métodos e técnicas. Lisboa: Fundação Calouste Gulbenkian, 2003. 
JAEGER, A. A.; JACQUES, K. Masculinidades e docência na educação infantil. Estudos Feministas, Florianópolis, v. 25, n. 2, p. 545-570, 2017. https://doi. org/10.1590/1806-9584.2017v25n2p545

MONTEIRO, M. K.; ALTMANN, H. Homens na Educação Infantil: olhares de suspeita e tentativas de segregação. Cadernos de Pesquisa, São Paulo, v. 44, n. 153, p. 720-741, 2014. https://doi.org/10.1590/198053142824

MORROW, V. Understanding gender differences in context: implications for young children's everyday lives. Children \& Society, v. 20, n. 2, p. 92-104, 2006. https://doi. org/10.1111/j.1099-0860.2006.00017.x

RAMOS, J. Um estudo sobre os professores homens da educação infantil e as relações de gênero na rede municipal de Belo Horizonte-MG. 2011. 139 f. Dissertação (Mestrado em Educação) - Pontifícia Universidade Católica de Minas Gerias, Belo Horizonte, 2011.

RAMOS, J. Gênero na educação infantil: relações (im)possíveis para professores homens. Jundiaí: Paco Editorial, 2017.

ROCHA, E. A.C. Por que ouvir crianças? Algumas questões para um debate científico multidisciplinar. In: CRUZ, S. H. V. (org.). A criança fala: a escuta de crianças em pesquisas. São Paulo: Cortez, 2008. p. 43-51.

SANTOS, S. V. S. dos. Socialização de gênero na educação infantil: uma análise a partir da perspectiva das crianças. 2016. 313f. Tese (Doutorado em Educação) Faculdade de Educação, Universidade Federal de Minas Gerais, Belo Horizonte, 2016.

SANTOS, S.V.S. Socialização de gênero na educação infantil: continuidades e rupturas vivenciadas pelas crianças na família, na igreja e na escola. Educação, Santa Maria,v. 42, n. 3, p. 731-750, set./dez. 2017. https://doi.org/10.5902/1984644428325

SANTOS, S. V. S. dos. Estrutura e agência nas interseções de gênero e infância: implicações para a Educação Infantil. Currículo sem Fronteiras, v. 18, n. 1, p. 380399, 2018.

SÃO PAULO. Projeto de Lei n.o 1.174, de 2019. Confere a profissionais do sexo feminino a exclusividade nos cuidados íntimos com crianças na Educação Infantil e traz outras providências. São Paulo: Assembleia Legislativa de São Paulo, Secretaria Geral Parlamentar, Sistema de Processo Legislativo, [2019]. Disponível em: https:// www.al.sp.gov.br/propositura/?id=1000292074. Acesso em: 10 fev. 2021.

SAYÃO, D.T. Relações de gênero e trabalho docente na educação infantil: um estudo de professores em creches. 2005. 274f. Tese (Doutorado em Educação) - Universidade Federal de Santa Catarina, Florianópolis, 2005.

SILVA, I. O.; LUZ, I. R. Meninos na Educação Infantil: o olhar das educadoras sobre a diversidade de gênero. Cadernos Pagu, Campinas, n. 34, p. 17-39, 2010. https://doi. org/10.1590/S0104-83332010000100003

SILVA, P. R. Não sou tio, nem pai, sou professor! A docência masculina na educação infantil. 2014.222f. Dissertação (Mestrado em Educação) - Universidade Estadual de Campinas, Campinas, 2014. 
SILVA, T. J. et al. Relazioni di genere, educazione della prima infanzia e cambiamenti sociopolitici in Brasile: contributi per uno stato dell'arte. Rivista Italiana di Educazione Familiare, v. 13, n. 2, p. 209-230, 2018. https://doi.org/10.13128/RIEF-24494

SOUSA, J. E. Homem docência com crianças pequenas: um olhar das crianças de um centro de educação infantil. In: REUNIÃO NACIONAL DA ANPED, 37., 2015, Florianópolis. Anais eletrônicos [...]. Florianópolis: ANPEd, 2015. Disponível em: http://37reuniao.anped.org.br/wp-content/uploads/2015/02/Trabalho-GT07-4232. pdf. Acesso em: $1^{\circ}$ mar. 2020.

SPRADLEY, J.P. Participant observation. Nova York: Holt, Rinehart and Winston, 1979.

THORNE, B. Gender play: girls and boys in schools. Nova Brunswick: Rutgers University Press, 1993.

VIEIRA, L.M. F. Creches no Brasil: de mal necessário a lugar de compensar carências rumo à construção de um projeto educativo. 1986. 366f. Dissertação (Mestrado em Educação) - Universidade Federal de Minas Gerais, Belo Horizonte, 1986.

WEST, C.; ZIMMERMAN, D. H. Doing gender. Gender and Society, v. 1, n. 2, p. $125-151,1987$.

\section{SOBRE O AUTOR}

Sandro Vinicius Sales dos Santos é doutor em educação pela Universidade Federal de Minas Gerais (UFMG). Professor da Universidade Federal dos Vales do Jequitinhonha e Mucuri (UFVJM).

E-mail: sandrovssantos@gmail.com

Conflitos de interesse: $\mathrm{O}$ autor declara que não possui nenhum interesse comercial ou associativo que represente conflito de interesses em relação ao manuscrito.

Financiamento: Coordenação de Aperfeiçoamento de Pessoal de Nível Superior (CAPES).

Recebido em 5 de julho de 2020 Aprovado em 2 de março de 2021 